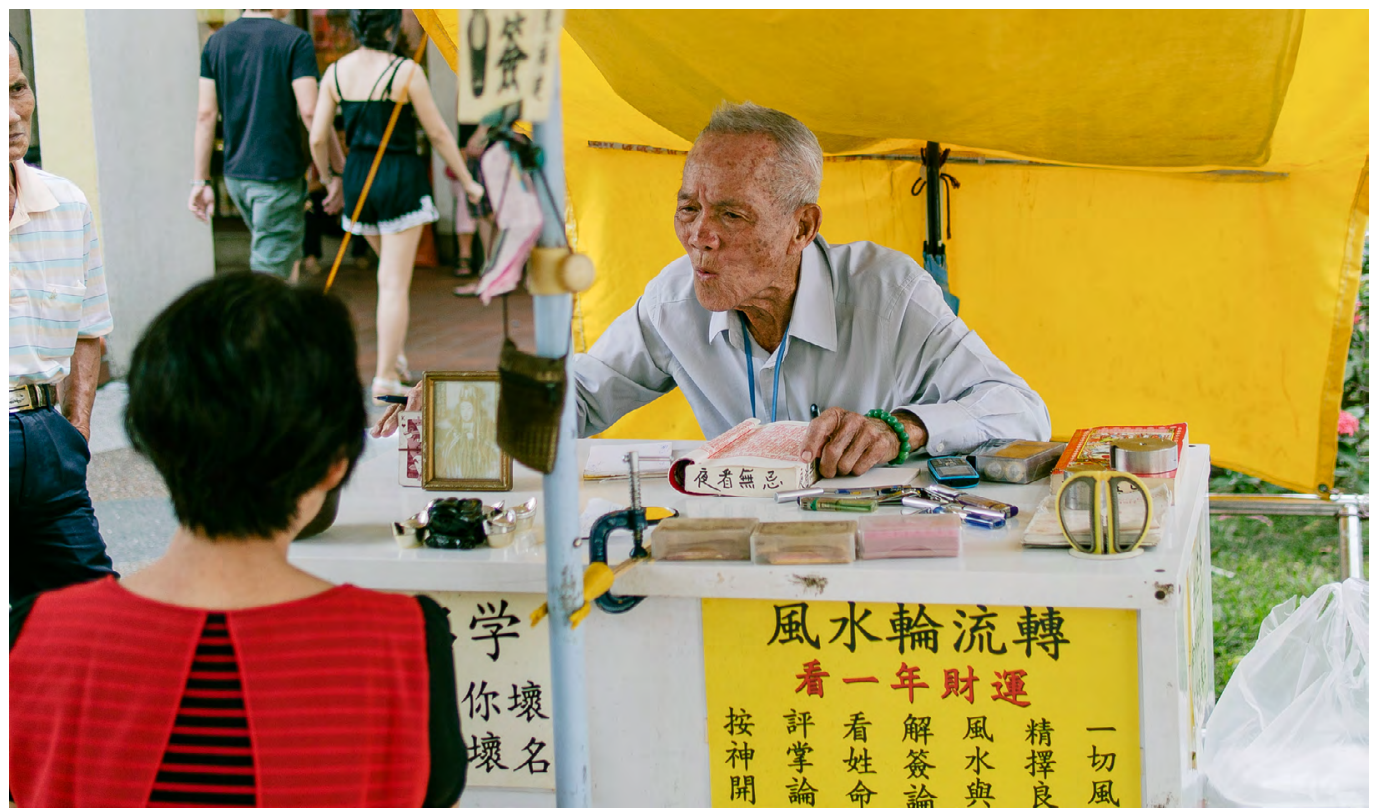

\section{The Yijing Ethic and the Spirit of Capitalism with Chinese Characteristics}

William MATTHEWS

Since the early days of economic reform in the 1980s, China has witnessed a revival of religious beliefs and practices. One of the most pervasive is fortune-telling, which has flourished by offering a means of decision-making in a rapidly changing and uncertain society. This article describes a popular method of fortune-telling using the classical text of the Yijing. It shows how fortunetelling's naturalistic worldview provides an excellent method for people to navigate day-today economic decisions by forecasting fortune in a way that is trustworthy and morally blameless, serving as a compass for uncertain times.
Fortune-teller. PC: Joel Sow.

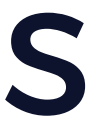
ince the 1980s, alongside the Reform and Opening Up of the Chinese economy and concomitant 'spiritual crisis' (精神危机), China has seen a revival of popular religious practices (Johnson 2017). This has included widespread interest in methods of fortune-telling with the Yijing (易 经), also commonly known as I Ching or Book of Changes, a two-thousand-year-old text on divination and cosmology that has exercised a historical influence in China comparable to that of the Bible in Europe. In fact, this revival of interest has spawned its own proliferation 
of scholarly analyses trying to make sense of China's 'ritual economy'-the resolutely intertwined practices of economic pursuits, religious convictions, kinship ties, and guanxi (关系) networks discussed at length by anthropologist Mayfair Yang $(2000 ; 2020)$ that seem to have put paid to assumptions about the rationalising effects of capitalism. 'Occult economics' indeed-but while other resurgent religious practices may well have something to do with a search for meaning in post-socialist capitalism, fortune-telling with the Yijing does not. Instead, it plays a very practical role in helping people participate in the challenges and opportunities contemporary society presents.

\section{Between Superstition and Science}

The Yijing's own revival peaked in the 'Yijing fever' (易经热 or 周易热) of the 1980s and 1990s, when the publication of new archaeological studies combined with the booming publishing sector to produce a proliferation of books on the subject (Redmond and Hon 2014). This continues today, with new editions of the text, guides adapting it for modern audiences, manuals for using its wisdom to promote good management practices, and, of course, guides to divination. It also remains a focus of scholarly enquiry, both as an object of historical and philosophical significance and as a source of knowledge or wisdom in its own right, the latter institutionalised as 'Changes studies' (易学), a dedicated academic field with its own research institutes as well as amateur associations (Matthews 2017).

However, while scholarship on the Yijing or its use as a source of philosophical 'wisdom' holds political legitimacy, this is not so much the case for its use in fortune-telling-which is where it truly speaks to everyday economic questions. Fortune-telling is considered 'superstition' (迷信) both by the state and by large sections of the public-but practitioners of course do not share this view, and often present it instead as 'scientific' (科学的) and therefore legitimate. As fortune-telling has returned to everyday life in China over the past four decades, it has regained something of the ubiquity it enjoyed before it was pushed underground by Maoism. The majority of people, if they have never consulted a fortuneteller themselves, will doubtless know someone who has, and many who do might well still refer to it as 'superstition' even as it helps them make key life decisions.

In fact, rather than appealing to the 'occult', Yijing divination relies on a very naturalistic explanation of how the world, and fortune-telling, works. This is what makes practitioners' assertions that it is 'scientific' persuasive. The Yijing itself contains 64 'hexagrams' (卦), diagrams of six broken or unbroken lines, which are made by combining eight three-line diagrams (trigrams, also 卦). The Yijing today comprises these, the obscure texts accompanying them, and commentaries, which explain that the sage-king $\mathrm{Fu} \mathrm{Xi}$ created the trigrams by observing patterns in nature, using these observations to derive constant principles of how the world works. Every possible circumstance could therefore be described by combining the trigrams, producing 64 basic kinds of situation. Fortunetellers today will still tell you that because the hexagrams are derived from observing the world, they can therefore be applied to any situation to explain what is going on and what will happen next. This is explained in terms of $q i$ (气), an energy-substance that constitutes everything in the cosmos, including thoughts and emotions. While the idea obviously does not come from physics, there is not a lot of difference between describing everything as being made of $q i$ and everything as being made of matter and energy-one does not need to invoke supernatural forces to subscribe to Yijing divination.

That assumes, though, that people who consult fortune-tellers need to 'believe' in it at all to find it useful. In fact, much of the time clients are reluctant to commit to 'believing' 
(相信) in it; as in forms of divination around the world, many of which do not have any worldviews attached to them at all, clients still use them to help make decisions or resolve conflicts (Boyer 2020). But if clients often do not really 'believe' in it, and it is widely considered superstitious or even fraudulent, why are people from all walks of life willing to spend money and time consulting fortunetellers at all? To understand how it plays a role in the everyday economics of contemporary China, we need to look closer at how Yijing fortune-telling works.

\section{Methods of Divination}

There are various methods of Yijing divination, but all rely on obtaining a hexagram, interpreted as a snapshot of the world from the perspective of the client at a particular point in time and space. This is used to gain information about the client's general circumstances and relationships, which can then be used to diagnose problems and offer advice. Most of my own research on this relates to a technique called 'six lines prediction' (六爻预测), the form of Yijing divination that most people are likely to encounter, typically by temples or large transport hubs-the former being frequented to pray for good fortune, and the latter likely relating to the potential uncertainties and possibilities of travel or labour migration. In a city like Hangzhou, where I did fieldwork, this costs between 20 and 50 yuan, with optional extras such as eightcharacters (八字) horoscopy, face-reading (面相), or even fengshui (风水) consultation. People ask a range of questions, but the most common enquiries relate to marriage, health, personal relationships, work, and money-in short, questions of pressing personal concern that produce difficult decisions or potential uncertainties.

Clients are told not to voice their question until after the procedure has been completed. This involves throwing three coins six times, giving the six lines of a hexagram. The diviner interprets this in terms of the kinds of $q i$ associated with each line, and the kinds of personal relationships that they indicate. Once this is done, the diviner will likely make some general comments on salient relationships revealed by the hexagram, and the client is invited to ask any specific questions. Let's take the enquiry of Mrs $\mathrm{Xu}$ (a pseudonym) as an example (described in detail in Matthews 2018). She got a hexagram that referred to her wealth. Each hexagram has two key lines, one for the enquirer (the 'generation line' 世爻) and one for the subject (the 'resonant line' 应 爻); in this case the generation line referred to 'wives and wealth' (妻财), and the resonant to 'brothers' (兄弟). The resonant line here also corresponded to Earth, and the generation line to Water-according to the cosmology of $q i$, Earth conquers Water. This meant that Mrs Xu's wealth was under threat from financial competitors, 'brothers' referring to people of equivalent social status to the enquirer.

Observing other correlations in the hexagram, the fortune-teller Master Tao noted that Mrs Xu's currently calm attitude to them would be beneficial; correlating the hexagram with Mrs Xu's horoscope based on her date of birth, he was able to give her a forecast. She was moving from a difficult year to two auspicious years, but would need to take care when dealing with these issues in the third year, as it would bring the influence of negative qi. So, Mrs Xu's financial concerns were explained in a way that integrated them closely with other aspects of her life (notably her health), and according to a natural pattern of changing fortune. She was given some responsibility within this-to pay attention to her health and finances in a specific period-but ultimately the ups and downs of her fortune, and the threat posed by outside influences, are explained in terms of the interaction between her own qi and that of the cosmos as a whole. She is granted enough agency to have some positive influence, but at the same time any blame for misfortune is externalised (even the threat from competitors is the product of cosmic forces). 


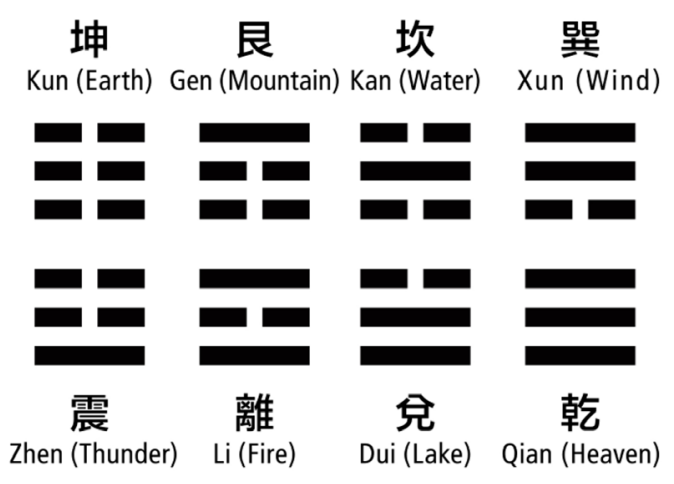

The building blocks of the Yijing, known as trigrams.

Mrs Chen was a small business owner who was interested in whether, and when, she could buy a new shop unit. In this case, Master Tao identified a 'mutually destructive' (相克 的) relationship between the generation line, representing Mrs Chen, and the resonant line, representing the owners of the shop she wanted to buy. In this case, the diagnosis was auspicious-while Mrs Chen explained she had been worrying about whether she could safely sell her old shop, Master Tao said there was no need. The shop would be hers in spite of the mutually destructive relationship-to deal with that, Mrs Chen should be patient, and refrain from discussing acquiring the shop for the next 50 days.

Here, we can again see how the consultation provides a combination of agency and assurance. Notably, both examples involve forecasting future auspicious and inauspicious times-this is crucial. Strictly speaking, sixlines prediction does not give a forecast of what will or will not happen. Instead, by considering the agricultural calendar (农历), based on cycles of qi that follow the same logic as the hexagrams, a client's current fortune can be taken into account in relation to forthcoming qi flows. That is, in both these cases, the client is offered a financial projection of sorts-but one based on cosmic principles rather than the stock market. Indeed, Master Tao would use a simplified version of Yijing divination occasionally to project likely earnings for the day.

\section{A Relational Theory of Economy}

Six-lines prediction has its own theory of economics, one that is well suited to use in the rapidly changing environment of contemporary Chinese capitalism. Considering all the uncertainty, instability, precarity, and opportunity that the current socioeconomic system presents for Chinese people, it is no surprise that a market has emerged to help people make sense of these conditions, which diviners are happy to fill. At the other end of the socioeconomic scale from Master Tao, plenty of fortune-tellers operate as consultants for highpowered business owners and other elites, and charge thousands of yuan for their services. Operating from their own offices or homes, they are less at risk of being moved along by the authorities when the state decides it wants to clear up visible superstition; in Hangzhou, these forced removals have increased since preparations for the 2016 G20 summit and appear to have developed into a general campaign to remove roadside businesses of any kind. Master Tao, for example, was permitted to continue fortune-telling provided he moved to the terrace of a nearby cafe, behind a hedge so he was not visible and would not attract a crowd. The irony of this was that he was forced finally to start using WeChat to communicate with clients, and pre-booked appointments soon filled far more of his schedule than had passing pedestrians.

As mentioned in Mrs Xu's example, 'wealth' in six-lines prediction is part of the category 'wives and wealth', betraying the sexual hierarchy of the context in which the method was developed from the Han dynasty onwards. However, while this means that the categories involved in discussing spousal relations vary for men and women, this does not seem to have 
an obvious impact on clients. The remaining relational categories all describe personal relationships-parents, brothers, children and grandchildren, officials, and ghosts-which can be used to categorise the connection of the client with any particular thing. So pets, for example, come under 'children and grandchildren' as they are dependent on care, and for women, husbands come under 'officials and ghosts' as in Confucian terms they hold authority over their wives.

This means that, in theory at least, women are likely to receive slightly more divinatory diagnoses concerning finances than men; for men, meanwhile, their relationship to their wives is equivalent to that with their money (or vice versa). Either way, though, wealth is an asset over which a client has some degree of control or influence. As we have seen, however, it can be contested. So, a person's relationship with their wealth, and by extension their financial fortune, has to be understood as part of their wider social relations. Economics, from the Yijing's point of view, cannot exist in isolation. Even more than that, one's relation to one's wealth is itself subject to the same wider cosmic forces as one's life circumstances overall, including one's other relationshipsand the nature of hexagram interpretation means it always offers information about other aspects of life as well. This does not mean that positive financial fortune necessarily coincides with, say, good health or luck in love, or indeed auspicious work relationships. But it does mean that all of these things have a common cause in the interaction of a person with cosmic $q i$. Because the forecast provided by a diviner is based on fixed principles about how this qi changes over time, a client's prospects for maintaining, improving, or losing their fortune are constrained. However, the diviner never tells a client what will unequivocally come to pass. Instead, final agency remains with the client-but they now know that if they take a certain course of action, it is more or less likely to improve or endanger their fortune.

\section{A Compass for Uncertain Times}

This tells us something about why the services of fortune-tellers remain in demand, and in fact flourish, in China today despite being labelled 'superstitious'. With so much uncertainty and opportunity in the temperamental context of Chinese capitalism, individuals are confronted with an overwhelming array of decisions, from seeking economic security, to household budgeting, to business ventures, to consumer choices. Fortune-telling helps to contain these decisions, give a limited range of optimal options, and take away an excessive degree of moral culpability by ascribing these conditions to a cosmic order while still allowing the client final agency over their decisions. Significantly, this is not about 'meaning' in the existential sense-the 'spiritual crisis' that popular religion, revived Confucianism, and nationalism have risen partly in response to. While diviners and clients might 'believe in' the cosmology of the Yijing, the fact that that cosmology is naturalistic and ultimately amoral means that any existential meaning must be brought along or read into it by the client. This actually enhances its utility as a way of rationalising decisions and limiting optionsone simply picks an optimum outcome from the paths available.

It is worth considering here something true of divination in general. As I have suggested in passing, and David Zeitlyn has discussed in more detail (2012), there is a genuine similarity between divination and financial forecasting, in that both use models of the world to diagnose features of the past and present and, assuming those models are accurate and constant, to predict future conditions and accordingly offer advice for action. This relates to the key feature of divination that explains why people use it at all: it is intuitively trustworthy. As anthropologist Pascal Boyer explains (2020), a key reason divination is found across societies, and throughout history, is that it produces statements that do not come from an individual 
person. People are constantly on the lookout for cues that they can trust others, or for possible reasons to doubt them-that is, we unconsciously pick up signals about whether or not another person is reliable. In divination, the statements come from the fortune-telling technique-the coins in the case of six-lines prediction, and the fixed referents of the hexagrams. We could say the same thing about the models employed in financial forecasting. This means that a key reason to doubt the statement is removed-clients can see that the fortune-teller has no control over how the coins fall (as a forecaster has no control of the outcomes of a model), so the potential for the statement being deceptive is reduced.

Now, as Charles Stafford points out, in contemporary Chinese society and the ritual economy in which it is enmeshed, a common topic of conversation is 'swindling people' (骗 人). The potential to exploit the trust of others granted by rapid economic liberalisation and the delayed development and poor implementation of protective regulations, coupled with incidents and widespread fears of fraud and con-artistry, have combined to erode levels of public trust in the system, adding to the sense of 'spiritual crisis'. Indeed, diviners themselves, as well as being labelled peddlers of 'superstition', are also subject to accusations of 'swindling people' by taking their money based on false beliefs (and may be prone to accusing others of doing so themselves). Ironically, though, in an environment pervaded by distrust, in which economic decisions must be weighed carefully based on potential ill intent or misinformation, divination offers a method that, in its own way, guarantees trustworthiness.

\section{A New Relevance}

Yijing divination has always been an important part of everyday life in China. That it has been revived over the past four decades is first and foremost to do with the relaxation of state control over 'superstition', but the economic changes of the reform era have created new contexts in which it becomes relevant and valued in people's lives. Diviners themselves have found new opportunities, and while clients embrace divination for the same broad reasons it has always been embraced, they do so to solve day-to-day problems whose nature reflects the specificities of contemporary Chinese capitalism. If $\mathrm{Mrs} \mathrm{Xu}$ or $\mathrm{Mrs}$ Chen and others like them feel they cannot trust the advice of others, particularly in the economic realm, they have the option of a detached fortune-telling technique that, regardless of whether they 'believe' in its cosmology, provides the assurance of neutrality, with the added bonus of blamelessness and just enough agency over one's future. 
This text is taken from Made in China Journal: Volume 5, Issue 2, 2020 , edited by Ivan Franceschini and Nicholas Loubere, published 2020 by ANU Press, The Australian National University, Canberra, Australia.

doi.org/10.22459/MIC.05.02.2020.11 